\title{
Comparative Mechanical Tests of Samples Obtained by the Domestic Experimental Unit Meltmaster $^{3 \mathrm{D}} \mathbf{- 5 5 0}$
}

\author{
A.V. Dub, V.V. Beregovsky, E.V. Tretyakov, S.A. Schurenkova \\ and A.V. Yudin
}

\begin{abstract}
The current development of the domestic engineering industry is closely connected with the development of new production technologies and metal processing methods, which corresponds to the transition of the industry to the sixth technological order. One of the priorities and strategically important directions of this development is the introduction of additive technologies into existing production chains. Currently, in the developing Russian market of 3D printing, there is a shortage of qualitative domestic industrial equipment and consumables materials (metallic powders). The present development of additive technologies in Russian companies is carried out with costly imported equipment based on the use of expensive imported consumables. To reduce the share of imported equipment in the Russian market effectively, the development of the technology and prototype model of the experimental unit MeltMaster ${ }^{3 \mathrm{D}}-550$ for precision manufacturing of responsible, bulky products with a complex profile based on advanced technologies of additive manufacturing by selective laser melting method (SLM).
\end{abstract}

Keywords 3D printing - Equipment - Selective laser melting - Metal powder

\footnotetext{
A.V. Dub $(\bowtie)$

JSC «Science and Innovations», Moscow, Russia

e-mail: alvdub@rosatom.ru

V.V. Beregovsky · E.V. Tretyakov · S.A. Schurenkova · A.V. Yudin

SSC RF JSC «RPA «CNIITMASH», Moscow, Russia

e-mail: vvberegovsky@cniitmash.com

E.V. Tretyakov

e-mail: evtretyakov@cniitmash.com

S.A. Schurenkova

e-mail: saschurenkova@cniitmash.com
}

A.V. Yudin

e-mail: avudin@cniitmash.com

(C) The Author(s) 2018

K.V. Anisimov et al. (eds.), Proceedings of the Scientific-Practical Conference

"Research and Development - 2016”, https://doi.org/10.1007/978-3-319-62870-7_36 


\section{Introduction}

Selective Laser Melting (SLM) is a new technology for producing complex-profile products, which allows obtaining a high density, high accuracy of geometric dimensions and mechanical properties of the corresponding molded materials [1]. The preformed layer of the metal powder is melted by laser energy followed by crystallization through extracting heat into massive building platform. Such layers are fused with each other, thereby forming complex three-dimensional products.

Over the past decade of the development of additive technologies a large number of scientific papers have been published, which describe manufacturing of samples and products made of various stainless steels by the selective laser melting. As a rule, authors give the following main process parameters that affect the quality of products and samples $[2,3]$ :

- original metal powder chemical: chemical composition, shape and size distribution of particles, the thickness of each melted layer for each production cycle;

- laser source: type, power, space-energy beam parameters (light intensity distribution, the size of the laser beam spot in the melting zone as a result of its divergence);

- characteristics of the production process: scanning speed, type of protective gas environment, choice of the type and parameters of the scanning strategy in each melted layer.

The authors of the article [4] state that the area of process parameters (laser power and scanning speed) should be determined for each material experimentally. Figure 1 shows the dependence of the laser power on the scanning speed indicating the area of technological modes of powder processing with austenitic stainless steel in which steady single vectors (tracks) must form.

Fig. 1 Field of technological modes [4]

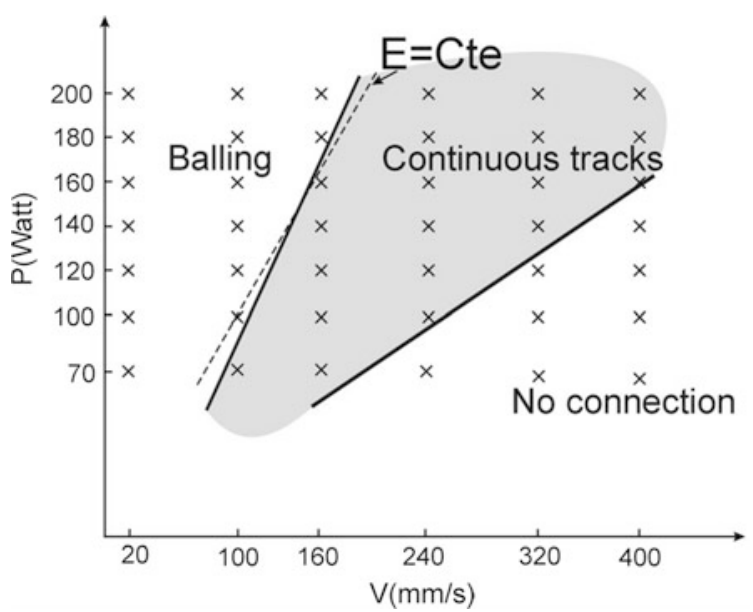


The authors of the article [5] carried out a series of experiments designed to produce bulky samples by combining the methods of «two zones» and «cross-hatch» with the following parameters: input laser power is $50 \mathrm{~W}$, thickness of the layer is 40 microns, scanning speed is $120 \mathrm{~mm} / \mathrm{s}$, and scanning step is 120 microns. The cylindrical samples were produced in accordance with ISO-7500/1 and their mechanical tests were done. The results are shown in Table 1.

The analysis of the mechanical properties of the samples produced with SLM from stainless steel powder (SS) 316L, showed excellent correspondence to mechanical properties of cast materials.

The study of the influence of the powder layer thickness and the direction of the location of the samples on the build platform during building on the mechanical characteristics of the samples from austenitic stainless steel 316L (see Table 2) was carried out and described in the paper [6]. For this purpose, a series of samples under the same process SLM conditions was produced. Mechanical properties of the samples made at horizontal and vertical positions are shown in Table 2.

It should be noted that both the elongation limit of samples UTS, $\sigma_{0.2}$ and samples with the layer thickness of 60,80 and 100 microns is higher than that of the samples produced with the thickness of 120 microns and 150 microns [7, 8]. However, the value of elongation for all samples does not reach the standard value of $40 \%$.

The authors [6] explain the increase of elongation and decrease of tensile when the layer thickness grows by the decrease in the number of layers, and as a result reduction in the number of tracks borders, which can be the place of the crack formation.

Table 1 Mechanical properties of SLM samples [5]

\begin{tabular}{l|l|l}
\hline Properties of the sample & \multicolumn{2}{|l}{$\begin{array}{l}\text { Material and method of sample } \\
\text { production preparation }\end{array}$} \\
\cline { 2 - 3 } & \multicolumn{2}{|l}{ SS 136L } \\
\cline { 2 - 3 } & SLM & Casting \\
\hline Tensile strength $(\mathrm{MPa})$ & $436 \pm 60$ & $480-560$ \\
\hline Yield strength $(0.2 \%)(\mathrm{MPa})$ & $366 \pm 50$ & $170-290$ \\
\hline Elongation $(\%)$ & $9 \pm 2$ & 40 \\
\hline
\end{tabular}

Table 2 Mechanical properties of samples [6]

\begin{tabular}{l|l|l|l|l|l|l}
\hline \multirow{2}{*}{$\begin{array}{l}\text { Layer } \\
\text { thickness }(\mu \mathrm{m})\end{array}$} & \multicolumn{3}{|l|}{ Horizontal position of sample } & \multicolumn{3}{l}{ Vertical position of sample } \\
\cline { 2 - 7 } & $\begin{array}{l}\text { UTS } \\
(\mathrm{MPa})\end{array}$ & $\begin{array}{l}\sigma_{0.2} \\
(\mathrm{MPa})\end{array}$ & $\begin{array}{l}\text { Elongation } \\
(\%)\end{array}$ & $\begin{array}{l}\text { UTS } \\
(\mathrm{MPa})\end{array}$ & $\begin{array}{l}\sigma_{0.2} \\
(\mathrm{MPa})\end{array}$ & $\begin{array}{l}\text { Elongation } \\
(\%)\end{array}$ \\
\hline 60 & 720 & 525 & 22 & 690 & 526 & 19 \\
\hline 80 & 735 & 532 & 32 & 695 & 529 & 16 \\
\hline 100 & 713 & 528 & 32 & 670 & 518 & 23 \\
\hline 120 & 700 & 473 & 32 & 660 & 513 & 20 \\
\hline 150 & 700 & 467 & 35 & 666 & 492 & 25 \\
\hline
\end{tabular}


Table 2 shows that the mechanical properties UTS, $\sigma_{0.2}$ and elongation of the samples grown at the horizontal position are higher than that of similar samples grown in vertical directions [6]. This indicates that the microstructure anisotropy SLM samples occurring during their building plays an important role in determining tensile properties. The similar results were obtained by the authors of the papers [7-10] on such SLM equipment as AM250 (Renishaw) and SLM250 (SLM-Solutions). The samples made at a horizontal position showed higher strength properties due to the tensile strain direction parallel to the cut of layers but perpendicular to dendrites. On the other hand, for the samples produced at the vertical position, the tensile load direction is normal to the layer formed. In this case, the width of the contact area (melting) between two adjacent layers increases with increasing layer thickness, which reduces mechanical characteristics.

The above mentioned works show the dependence of mechanical characteristics of the material on such parameters as layer thickness and direction of product made of powders of austenitic stainless steels by SLM. This article describes the dependence of the material density and its mechanical characteristics on the basic technological parameters of layer building on the example of the samples made of stainless steel 316L, produced on the pilot layer build-up unit by SLM method called MeltMaster ${ }^{3 \mathrm{D}}-550$.

\section{Experiment}

\section{Equipment Description}

The layer build-up process of samples by SLM method took place on the prototype model of the unit MeltMaster ${ }^{3 \mathrm{D}}-550$ [11] developed and manufactured by the JSC «RPA «CNIITMASH», with the financial support of the Ministry of Education and Science of the Russian Federation (Unique Identifier PNIER RFMEFI58214H0004). Table 3 shows the main technical characteristics of MeltMaster ${ }^{3 \mathrm{D}}-550$ in comparison with the industrial units of the world leaders in the field of producing equipment for 3D printing from metallic powders.

Figure 2 shows a general view of the prototype model of MeltMaster3D-550.

For the preparation and maintenance of layer-by-layer manufacturing of a product with a complex profile using MeltMaster ${ }^{3 \mathrm{D}}-550$ in the JSC «RPA «CNIITMASH», the original specialized software, which includes two software modules «SLM-Simulation» and «SLM-Production» was developed.

The functionality of the software includes the automation of all stages of layered manufacturing of products based on the original 3D-model. The following operations are performed in the program «SLM-Simulation»: selection/input of the configuration parameters; check/adjustment of 3D-model; location of 3D-model on the technological platform; cutting 3D-model into layers; hatching in accordance with the chosen strategy; building a technology support; generation of the control code. 
Table 3 Technical characteristics of MeltMaster ${ }^{3 \mathrm{D}}-550$

\begin{tabular}{|c|c|c|c|}
\hline \multirow[t]{2}{*}{ Parameters/name } & $\begin{array}{l}\text { JSC «NPO } \\
\text { «SNIITMASH» }\end{array}$ & EOS & SLM-Solutions \\
\hline & MeltMaster $^{3 \mathrm{D}}-550$ & $\begin{array}{l}\text { EOS M } 400 \\
(\text { EOS M 400-4) }\end{array}$ & SLM500 \\
\hline $\begin{array}{l}\text { Chamber dimensions, } \\
\mathrm{mm}\end{array}$ & $550 \times 450 \times 450$ & $400 \times 400 \times 400$ & $500 \times 280 \times 365$ \\
\hline $\begin{array}{l}\text { Number and power of } \\
\text { lasers, pc./kW }\end{array}$ & $\begin{array}{l}1 / 1 \\
2 / 0.5+1\end{array}$ & $\begin{array}{l}1 / 1 \\
4 / 0.4\end{array}$ & $\begin{array}{l}2 \times 0.4 \\
(\text { или } 2 \times 0.7) ; \\
4 \times 0.4 \\
(\text { или } 4 \times 0.7)\end{array}$ \\
\hline Optical system & $\begin{array}{l}3 \text {-axis optics/2 } \\
\times \text { F-Theta }\end{array}$ & $\begin{array}{l}\text { F-Theta/ } 4 \times \text { F-Theta, } \\
\text { high-speed scanner }\end{array}$ & 3-axis optics \\
\hline $\begin{array}{l}\text { Thickness of a layer } \\
(\mu \mathrm{m})\end{array}$ & $20-250$ & $20-150$ & $20-75$ \\
\hline Productivity $\left(\mathrm{cm}^{3} / \mathrm{h}\right)$ & $15-100$ & 100 & 105 \\
\hline $\begin{array}{l}\text { Dimensions } \\
\mathrm{W} \times \mathrm{D} \times \mathrm{H}(\mathrm{mm})\end{array}$ & $\begin{array}{l}2938 \times 2040 \\
(2488) \times 3000\end{array}$ & $4181 \times 1613 \times 2355$ & $5200 \times 2800 \times 2700$ \\
\hline Applied materials & \multicolumn{3}{|c|}{$\begin{array}{l}\text { stainless and tool steel, titanium, and titanium alloys, aluminum alloys, } \\
\text { superalloys }\end{array}$} \\
\hline $\begin{array}{l}\text { Delivery dates } \\
\text { (months) }\end{array}$ & $5-6$ & $6-7$ & $6-7$ \\
\hline
\end{tabular}

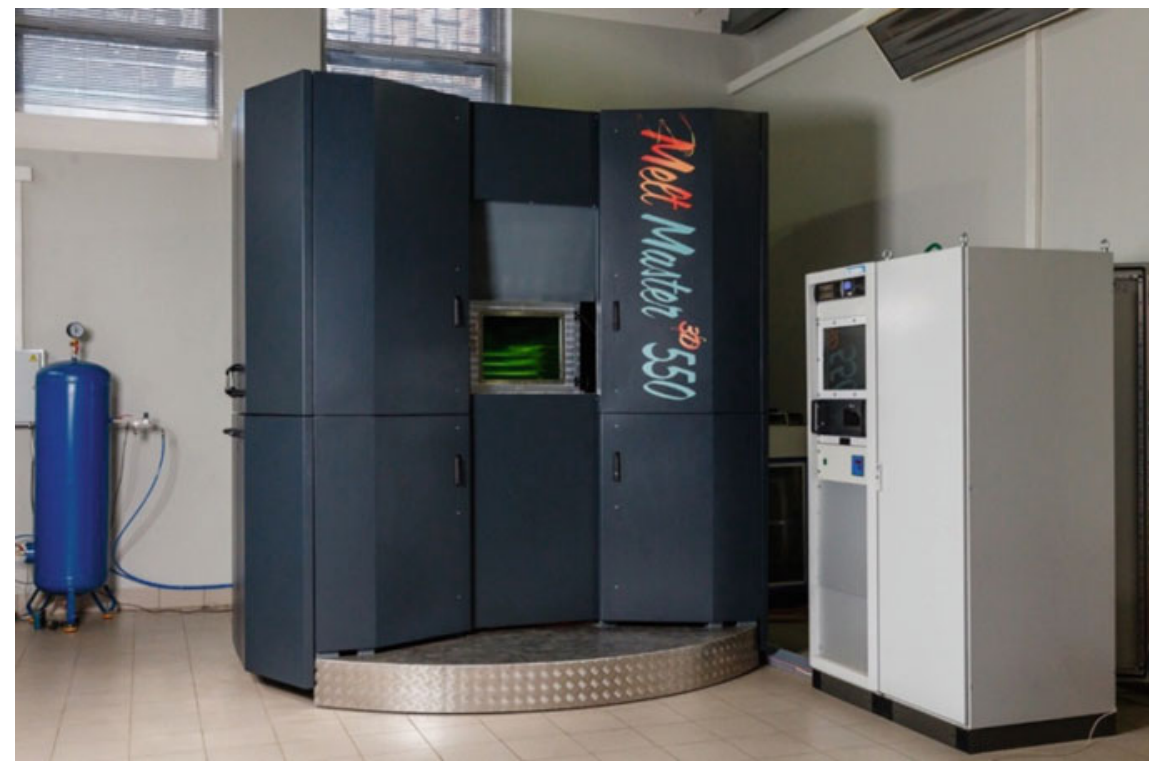

Fig. 2 General view of MeltMaster3D-550 
The control code that describes the parameters necessary for parts production and coordinate ways of scanning on each layer is the result of using the program «SLM-Simulation».

The program «SLM-Production» provides automatic smooth functioning of the layered build-up unit MeltMaster ${ }^{3 \mathrm{D}}-550$.

\section{Experimental Technique}

The samples were prepared in the layered build-up experimental unit of selective laser melting MeltMaster ${ }^{3 \mathrm{D}}-550$ with austenitic stainless steel powder $316 \mathrm{~L}$.

Microstructural studies were conducted on the SLM samples prepared in the form of rectangular parallelepipeds with the dimensions $3 \times 3 \times 15 \mathrm{~mm}$. The hatching was performed with a simple one-pass strategy.

To evaluate the critical scanning speed the following approach was used (1) [12]:

$$
\Delta t_{\mathrm{HOM}} \approx \frac{\left\langle r_{\text {powders }}\right\rangle^{2}}{4 \cdot \alpha}
$$

where $\Delta \mathrm{t}_{\text {ном }}$-time alignment in the particle temperature, $\left\langle r_{\text {powders }}\right\rangle$-average radius of the powder particles, $\alpha$-temperature conductivity of bulky powder material $\left(\mathrm{mm}^{2} / \mathrm{s}\right)$.

The laser exposure time must be greater than the time of homogenization. Then the critical scanning speed can be estimated with the following equation:

$$
V_{\text {scan }}<\frac{8 \cdot \alpha \cdot\left(\frac{1}{\mathrm{e}^{2}} d_{l}+\left\langle r_{\text {powders }}\right\rangle\right)}{\left\langle r_{\text {powders }}\right\rangle^{2}}
$$

where $\alpha$-thermal conductivity of the bulk material $\left(\mathrm{mm}^{2} / \mathrm{s}\right), d_{1}-$ the size of the laser spot on the surface of the powder layer, $\left\langle r_{\text {powders }}\right\rangle$-the average radius of the powder particles.

Thus, for the above conditions, the scanning speed must be less than $1200 \mathrm{~mm} / \mathrm{s}$. On this basis, the following technological parameters for producing experimental samples were proposed: the scanning speed from 100 to $1000 \mathrm{~mm} / \mathrm{s}$ and the laser power from 154 to 491 watts.

The samples were made (in accordance with GOST (State Standards) 1497-84) in two process modes for mechanical testing. Mode 1: the laser power is $264 \mathrm{~W}$, the scanning speed is $600 \mathrm{~mm} / \mathrm{s}$; Mode 2: the laser power is $264 \mathrm{~W}$; the scanning speed is $540 \mathrm{~mm} / \mathrm{s}$. The thickness of the layers during the production of all the samples was 50 microns. For the first group of samples, the hatching was carried out with a simple one-pass strategy with $160 \mathrm{~mm}$ scanning pitch and the rotation angle of $90^{\circ}$ when moving to the next layer. 
Table 4 Elemental composition of the austenitic steel 316L powder

\begin{tabular}{l|l|l|l|l|l|l|l|l|l}
\hline \multirow{2}{*}{ Powder } & \multicolumn{2}{l}{ Mass content (\%) } \\
\cline { 2 - 11 } & $\mathrm{Fe}$ & $\mathrm{Cr}$ & $\mathrm{Ni}$ & $\mathrm{Mo}$ & $\mathrm{Mn}$ & $\mathrm{Si}$ & $\mathrm{P}$ & $\mathrm{C}$ & $\mathrm{S}$ \\
\hline $316 \mathrm{~L}$ & 66.2 & 19.4 & 11.4 & - & 1.9 & 1.1 & $*$ & $*$ & $*$ \\
\hline
\end{tabular}

*not determined

The selective laser melting process samples took place in the atmosphere of nitrogen with the residual oxygen concentration of less than $0.07 \%$.

\section{Characteristics of the Original Material}

The elemental composition of 316L steel powder was determined by the micro $\mathrm{X}$-ray analysis. The results of the powder steel $316 \mathrm{~L}$ studies are presented in Table 4.

The powder particles have a rounded shape. The average estimated value of the powder roundness is 1.5 with the standard deviation of 0.5 . The dimensions of the powder particles range from 20 to 40 microns.

\section{Methodology of the Study}

\section{Density Determination}

The sample density was determined by hydrostatic weighing method [GOST 15139-69 Methods for determining density (bulk density)].

Prior to hydrostatic weighing samples were covered with a thin layer of varnish tsapon. The distilled water was used as the immersion liquid. To control the density of air and water accurately approximated dependencies on the temperature were used. A series of weighing was performed for each sample. The true value of the density was chosen as average among three densities. The error of density measurement was calculated by the Least Square Method and was less than 3\% for all the samples.

The samples were weighed in air and distilled water with high precision analytical scales $210 \mathrm{G} \times 0.1 \mathrm{Mg}$ (accuracy $\pm 0.0001 \mathrm{~g}$ ), with the special rigging. The sample density was calculated with the following formula (3):

$$
\rho_{\text {sample }}=\frac{m_{\text {in air. }}\left(\rho_{\text {water }}+\rho_{\text {air }}\right)}{m_{\text {in air. }}+m_{\text {in water }}}+\rho_{\text {air }},
$$




\section{Mechanical Tests}

The mechanical tests were done in accordance with GOST 1497-84 «Testing Stretching Methods».

The universal testing machine Z250 produced by the company Zwick (Germany) in combination with the automatic sensor of longitudinal deformation, high-temperature furnace and heat chamber was used during the experiments.

\section{Results and Discussion}

In the manufacturing process of bulk samples by SLM method the following parameters were changed: laser power from 154 to $491 \mathrm{~W}$, scanning speed from 100 to $1000 \mathrm{~mm} / \mathrm{s}$ (with the step of $100 \mathrm{~mm} / \mathrm{s}$ ). To compare the conditions for obtaining samples with different technological parameters, it is necessary to determine the contribution of specific laser energy. Density measurement results of samples made under the different process SLM conditions are presented in the diagram showing the dependence of sample density on the specific energy (Fig. 3).

The evaluation of the specific laser energy for each tested sample was carried out according to the formula (4) [13]:

$$
E_{\mathrm{sp}}=P /(V \cdot h)
$$

where $P$-laser power, $V$ - scanning speed, $h$-diameter of the laser beam.

The analysis of dependency of the sample density on the specific laser energy showed that when the energy changes from 1 to $3 \mathrm{~J} / \mathrm{mm}^{2}$ density increases sharply, but the density is less than $90 \%$. By increasing the energy from 3 to $12 \mathrm{~J} / \mathrm{mm}^{2}$ density also increases, but with a less dependence. Further increases of specific

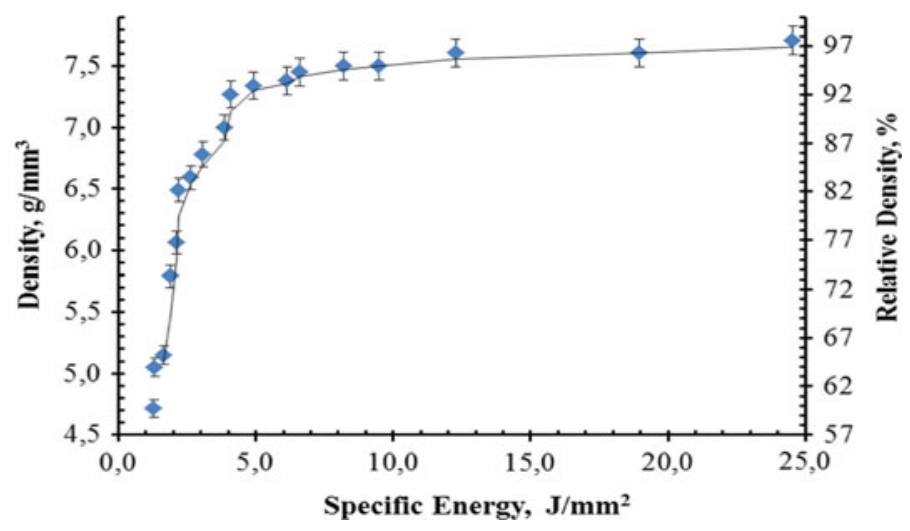

Fig. 3 Dependence of the sample density on the input specific energy 
energy practically do not lead to increase in sample density. We can conclude that the optimum value of the laser energy is in the range of $8-12 \mathrm{~J} / \mathrm{mm}^{2}$. These values are coordinated with the data, which were obtained on equipment EOSINT M270 and contained in the published articles, and have a similar character of the sample density dependence on the specific energy [14].

\section{Microstructure Study}

The results of the microstructure study of samples produced with the input specific energy to $3.0 \mathrm{~J} / \mathrm{mm}^{2}$ show the presence of open macropores. The samples made with the input energy density from 3.0 to $8.0 \mathrm{~J} / \mathrm{mm}^{2}$ are characterized by a 100-micron pore size. The layered structure also takes place. The samples made with the input specific energy from 8 to $12 \mathrm{~J} / \mathrm{mm}^{2}$ are characterized by the presence of micropores. The samples produced with the specific energy from 12 to $25 \mathrm{~J} / \mathrm{mm}^{2}$ have micropores and remelting tracks. The pore distribution, in this case, is random. Figure 4 shows a typical microstructure of samples with micropores and remelting on the example of the sample produced with the specific energy $11 \mathrm{~J} / \mathrm{mm}^{2}$.

In all the samples observed directed dendritic segregation and fine-grained areas took place. This structure is the result of the fast directionally crystallization during selective laser melting.

(a)

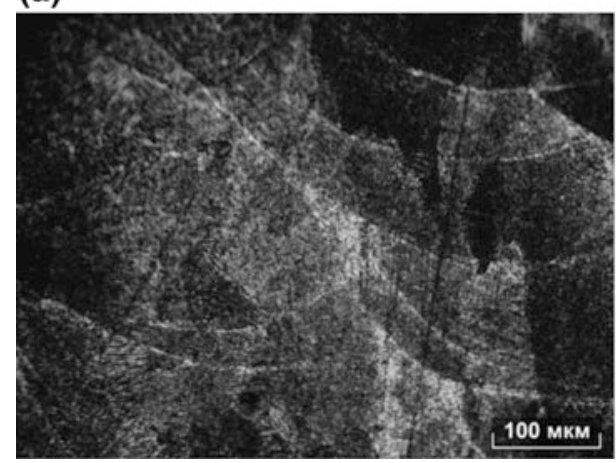

(b)

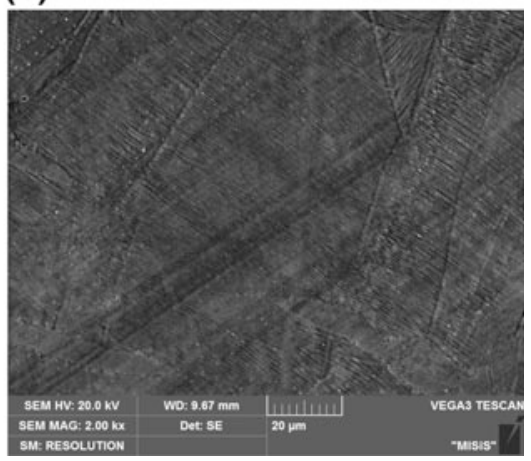

Fig. 4 Typical microstructure of samples: optical microscopy (a), SEM (b) 
Table 5 Mechanical properties of SLM samples

\begin{tabular}{l|l|l|l|l|l|l}
\hline Mode & $\sigma_{0.2}(\mathrm{MPa})$ & Error $(\%)$ & UTS $(\mathrm{MPa})$ & Error $(\%)$ & $\delta(\%)$ & Error $(\%)$ \\
\hline 1 & 466 & 1.38 & 604 & 2.02 & 18.93 & 2.31 \\
\hline 2 & 461 & 1.30 & 601 & 1.07 & 16.87 & 2.42 \\
\hline
\end{tabular}

\section{Mechanical Tests}

The relative density of the samples produced in the first process mode is $97.4 \%$ $( \pm 0.6 \%)$, in the second mode is $98.0 \%( \pm 0.1 \%)$ (relative density was calculated on the basis of pycnometric density of the stainless steel powder (SS) $316 \mathrm{~L}$ $7.93 \mathrm{~g} / \mathrm{cm}^{3}$ ).

The mechanical tests show that the samples produced with the simple one-pass strategy, have a strength comparable to molded material, but at the same time insufficient elongation (see Table 5).

Table 5 shows that the elongation is lower in the second process mode. This is due to higher residual thermal stresses resulting from the application of more specific energy and a possible double remelting during laser layer scanning.

\section{Conclusion}

The parameters the prototype model of the experimental equipment MeltMaster ${ }^{3 \mathrm{D}}-550$ designed by JSC «RPA «CNIITMASH» is on par with the main representatives of this class of such equipment currently presented in the $3 \mathrm{D}$ printing market from metal powders.

The modular architecture of MeltMaster ${ }^{3 \mathrm{D}}-550$ provides the production of numerous units with a high potential for adaptation and integration into existing production lines of machine-building enterprises, as well as without additional complex modernization will allow advancing to robotic digital productions on the basis of one or more identical units.

The experimental studies of the technological modes of metal powder selective laser melting based on the austenitic stainless steel 316L in MeltMaster ${ }^{3 \mathrm{D}}-550$ have shown the possibility to produce high-density samples. Moreover, the required scanning step has been calculated: when the powder layer thickness is 50 microns it is equal to 160 microns.

The dependence of the sample density on the laser power (input specific energy) and the scanning speed was identified. The optimum range of the input specific energy from 8 to $12 \mathrm{~J} / \mathrm{mm}^{2}$ was determined. These results are consistent with the data presented in the paper [14].

The study of SLM sample mechanical properties has shown that the tensile strength UTS $(600 \mathrm{MPa})$ and yield strength $\sigma_{0.2}(460 \mathrm{MPa})$ are greater than the corresponding values (480-560 MPa, 170-290 MPa) for cast materials. At the 
same time, the elongation of the product at the level of $18 \%$ within the error meets the requirements for construction materials.

On the basis of these results can also be concluded that the physical and mechanical properties of materials produced on the experimental unit MeltMaster $^{3 \mathrm{D}}-550$ are comparable with similar characteristics of materials, produced by using imported industrial equipment of such manufacturers as SLM-Solutions, Renishaw, EOS.

This work was financially supported by the Ministry of Education and Science of the Russian Federation (Unique Identifier PNIER RFMEFI58214H0004).

Acknowledgements The research is carried out with the financial support of the state represented by the Ministry of Education and Science of the Russian Federation. Agreement no. 14.582.21.0004 03 Oct. 2014. Unique project Identifier: RFMEFI58214X0004.

\section{References}

1. Liu, Y., Yang, Y., Wang, D.: A study on the residual stress during selective laser melting (SLM) of metallic powder. Int. J. Adv. Manuf. Technol., 1-10 (2016)

2. Volosov, M.A., Okounkov, A.A.: Ways of optimization of selective laser melting process by selecting the laser beam processing strategies. Bull. Samara Sci. Cent. Russ. Acad. Sci. 14 (2), 587-591 (2012)

3. Yadroitsev, I., Bertrand, P., Smurov, I.: Parametric analysis of the selective laser melting process. Appl. Surf. Sci. 253(19), 8064-8069 (2007)

4. Kruth, J.P.: Binding mechanisms in selective laser sintering and selective laser melting. Rapid Prototyp. J. 11(1), 26-36 (2005)

5. Smurov, I.J., Movchan, I.A., Yadroytsev, I.A., Okounkov, A.A., Cherkasova, N.Y., Antonenkova, G.V.: Additive laser production. Experimental studies. Vestnik MSTU "STANKIN" (1) 36-38 (2012)

6. Ma, M.: Layer thickness dependence of performance in high-power selective laser melting of 1Cr18Ni9Ti stainless steel. J. Mater. Process. Technol. 215, 142-150 (2015)

7. Guan, K.: Effects of processing parameters on tensile properties of selective laser melted 304 stainless steel. Mater. Des. 50, 581-586 (2013)

8. Casati, R., Lemke, J., Vedani, M.: Microstructure and fracture behavior of $316 \mathrm{~L}$ austenitic stainless steel produced by selective laser melting. J. Mater. Sci. Technol. 32(8), 738-744 (2016)

9. Hanzl, P., et al.: The influence of processing parameters on the mechanical properties of SLM parts. Procedia Eng. 100, 1405-1413 (2015)

10. Mertens, A., et al.: Mechanical properties of alloy Ti-6Al-4V and of stainless steel $316 \mathrm{~L}$ processed by selective laser melting: influence of out-of-equilibrium microstructures. Powder Metall. 57(3), 184-189 (2014)

11. Beregovsky, V.V., Tretyakov, E.V., Schurenkova, S.A.: Equipment for the layer-production of complex articles by selective laser melting MeltMaster ${ }^{3 \mathrm{D}}-550$. Additive technology: present and future. Materials of the II International conference. FSUE «VIAM» SRC RF. p. 22 (2016)

12. Fischer, P., et al.: Pulsed laser sintering of metallic powders. Thin Solid Films 453, 139-144 (2004) 
13. Olakanmi, E.O.: Selective laser sintering/melting (SLS/SLM) of pure $\mathrm{Al}, \mathrm{Al}-\mathrm{Mg}$, and $\mathrm{Al}-\mathrm{Si}$ powders: effect of processing conditions and powder properties. J. Mater. Process. Technol. 213(8), 1387-1405 (2013)

14. Spierings, A.B., Levy, G.: Comparison of density of stainless steel 316L parts produced with selective laser melting using different powder grades. In: Proceedings of the Annual International Solid Freeform Fabrication Symposium. Austin, TX, pp. 342-353 (2009)

Open Access This chapter is licensed under the terms of the Creative Commons Attribution 4.0 International License (http://creativecommons.org/licenses/by/4.0/), which permits use, sharing, adaptation, distribution and reproduction in any medium or format, as long as you give appropriate credit to the original author(s) and the source, provide a link to the Creative Commons license and indicate if changes were made.

The images or other third party material in this chapter are included in the chapter's Creative Commons license, unless indicated otherwise in a credit line to the material. If material is not included in the chapter's Creative Commons license and your intended use is not permitted by statutory regulation or exceeds the permitted use, you will need to obtain permission directly from the copyright holder.

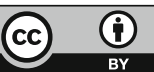

